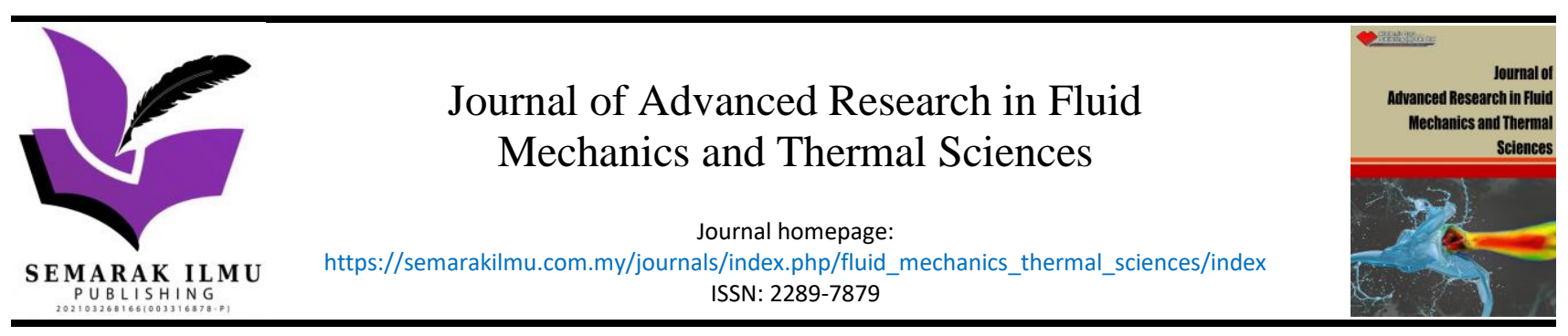

\title{
Compressor Piping Design Effect on Vibration Data
}

\author{
Aji Suryadi ${ }^{1}$, Yanuar $^{1,}{ }^{*}$, Gunawan $^{1}$ \\ Department of Mechanical Engineering, Fakultas Teknik, Universitas Indonesia, 16424, Depok, Indonesia
}

\section{ARTICLE INFO}

\section{Article history:}

Received 9 May 2021

Received in revised form 9 August 2021

Accepted 25 August 2021

Available online 18 October 2021

\section{Keywords:}

Screw compressor; Fluid dynamics; Condensation; Vibration; Backflow

\section{ABSTRACT}

\begin{abstract}
One of the systems for oil and gas production supports is the nitrogen compression system. Problem found that condition of the compressor has high vibration with the maximum overall the first compressor is $9,813 \mathrm{~mm} / \mathrm{s}$ RMS, the second compressor is $7,439 \mathrm{~mm}$ / s RMS, the third compressor is 7,430 mm / s RMS, the fourth compressor is $13.47 \mathrm{~mm} / \mathrm{s}$ RMS, the fifth compressor is $13,220 \mathrm{~mm} / \mathrm{s}$ RMS, and sixth compressor already damaged. This research will discuss the nitrogen compression process in terms of the characteristics of the output fluid flow from the compressor using computational fluid dynamics. The first piping system shows that the standby compressor's flow has a higher pressure reaching 10.72 - $11.82 \mathrm{~Pa}$ but it is still acceptable. The second piping system with two compressors in operation shows that the pipeline flows in the opposite direction with high pressure. Flow turbulence occurs, resulting in a higher speed. The highest pressure in the pipeline reaches $44.79 \mathrm{~Pa}$, mostly at the fifth and sixth compressors. The conclusion from this research there is high pressure backflow when one compressor stops and another compressor start running. Prevents direct pressure to the compressor or the condensed fluid from the gas flowing and entering the compressor used valve addition.
\end{abstract}

\section{Introduction}

Oil and gas energy production supports the needs of all people and societies in the world. Production process support systems are very complex because it is composed of many types of equipment and components such as electric motor, pump, valve, piping, and other. These constituent components require precise design that is continuous from one component to another. The precision of design and calculation will significantly affect the performance of equipment and system, which can cause the expected rate cannot be reach. One of the supporting systems for the oil and gas production process is the compression system [1-2]. The compression system in a plant aims to make the gas have a smaller volume with the same amount so that the transfer process from one place to another is more efficient.

The piping system on the nitrogen compressor shows that there is possibility backflow to the standby equipment [3-4]. Besides, the phenomenon of turbulence in pipe flow caused by boundary condition on pipe-wall and also appears confluence of two flows and the influence of flow velocity

\footnotetext{
* Corresponding author.

E-mail address: yanuar@eng.ui.ac.id

https://doi.org/10.37934/arfmts.88.1.94108
} 
[5-12]. The pressure on the backflow flow is very high, and it will cause nitrogen gas leading to standby equipment being condensate [13-16]. In addition to the condensation of nitrogen gas, nitrogen fluid gas provides high pressure to the screw on the compressor to affect the material life of the screw compressor and also can be caused of leakage [17-20]. Another consequence of the nitrogen gas condensing into liquid is contamination in the compressor, where it should only compress the gas. In this condition, there is liquid nitrogen causing an impact pressure on the compressor material, causing friction after the liquid nitrogen damages the previous material [21].

Hypothesis above found that operating conditions indicate that the nitrogen compressor has a high vibration value above-normal conditions based on the standard measurements made on the high-pressure stage compressor and low-pressure stage compressor and the respective inboard and outboard bearings $[22,23]$. High vibration can cause by high impact and friction at screw compressor and also flow turbulence-cavitation. Damage can occur due to the high impact on the constituent parts of the compressor, which causes more significant potential and greater friction between components. The amount of this impact value will accelerate each part wear and tear other parts. The case study that becomes the reference is the engine vibration value measured at maximum engine load conditions.

This research will discuss the nitrogen compression process in terms of the characteristics of the output fluid flow from the compressor. Analyzing the fluid flow characteristics of the existing piping system and make suggestions regarding the design of the piping system or valve system. Compressor output configuration can be changes the piping system or other methods to solve the problem.

\section{Methodology}

Vibration data was collected using CSI 2130/2140 equipment and vibration analysis software AMS Machinery Manager. Vibration data collection at the compressor side with several measurement points: bearing male low-pressure compressor, bearing female low-pressure compressor, bearing male high-pressure compressor, and bearing female high-pressure compressor. Each male and female compressor collection data on the drive end and non-drive end bearing positions.

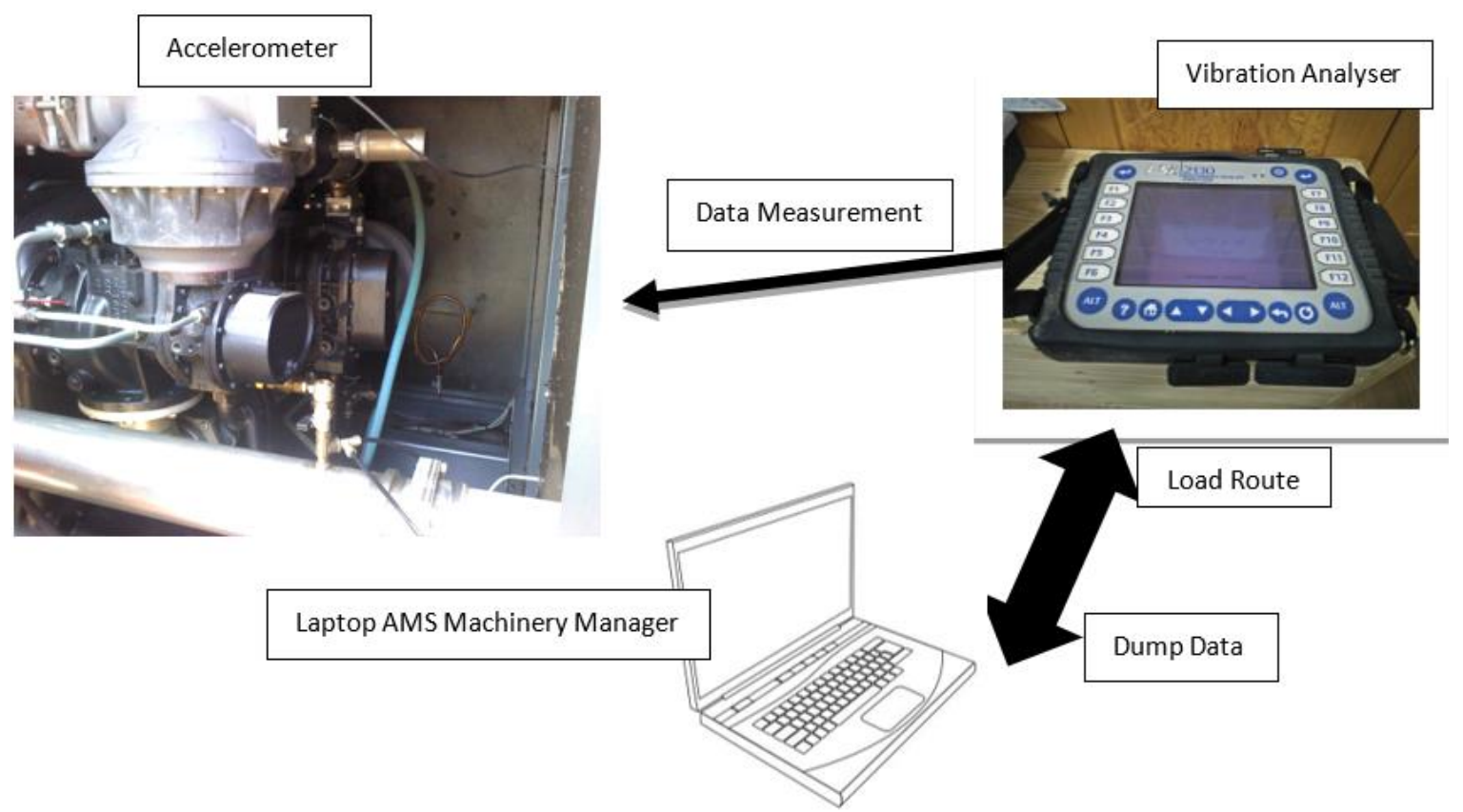

Fig. 1. Research Flow Chart 
Load Route is the process of sending domain data and configuration analysis setup for the process of retrieving vibration data of electric motors on inboard motors and outboard motors. Dump data is the process of sending data after vibration measurements are made and stored in the machine vibration analysis software.

Testing the pipe flow model is carried out by simulating the model using computational fluid dynamics software. Data analysis is obtained from pipe flow testing with several input flows with a fixed output. Then look at the flow and pressure that goes to the standby equipment as a parameter to analyze.

\section{Case Study}

\subsection{Equipment Vibration Data}

Table 1 show the condition of the compressor has high vibration with the following maximum data. The first compressor is a maximum overall of $9,813 \mathrm{~mm} / \mathrm{s} R M S$, the second compressor is a maximum overall of 7,439 mm / s RMS, the third compressor is a maximum overall of 7,430 mm / s RMS, the fourth compressor is a maximum overall of $13.47 \mathrm{~mm} / \mathrm{s}$ RMS, and the fifth compressor overall, 13,220 mm / s RMS. Based on the recommended standards for compressors, the maximum upper limit of the vibration value is $12 \mathrm{~mm} / \mathrm{s}$ RMS.

Table 1

Compressor vibration data value

\begin{tabular}{|c|c|c|c|c|c|c|c|c|c|}
\hline \multicolumn{4}{|c|}{ 1st Compressor Valve System } & \multicolumn{6}{|c|}{ 2nd Compressor Valve System } \\
\hline \multicolumn{2}{|c|}{ Compressor 1} & \multicolumn{2}{|c|}{ Compressor 2} & \multicolumn{2}{|c|}{ Compressor 3} & \multicolumn{2}{|c|}{ Compressor 4} & \multicolumn{2}{|c|}{ Compressor 5} \\
\hline Point & $\begin{array}{l}\mathrm{mm} / \mathrm{s} \\
\mathrm{RMS}\end{array}$ & Point & $\begin{array}{l}\mathrm{mm} / \mathrm{s} \\
\mathrm{RMS}\end{array}$ & Point & $\begin{array}{l}\mathrm{mm} / \mathrm{s} \\
\mathrm{RMS}\end{array}$ & Point & $\begin{array}{l}\mathrm{mm} / \mathrm{s} \\
\mathrm{RMS}\end{array}$ & POINT & $\begin{array}{l}\mathrm{mm} / \mathrm{s} \\
\mathrm{RMS}\end{array}$ \\
\hline $\mathrm{C} 1 \mathrm{H}$ & 4.921 & $\mathrm{C} 1 \mathrm{H}$ & 3.374 & $\mathrm{C} 1 \mathrm{H}$ & 7.322 & $\mathrm{C} 1 \mathrm{H}$ & 15.4 & $\mathrm{C} 1 \mathrm{H}$ & 5.128 \\
\hline C1V & 3.09 & C1V & 3.89 & C1V & 3.469 & C1V & 7.071 & C1V & 4.368 \\
\hline C1A & 4.871 & $\mathrm{C} 1 \mathrm{~A}$ & 3.528 & C1A & 6.127 & C1A & 8.715 & C1A & 5.596 \\
\hline $\mathrm{C} 2 \mathrm{H}$ & 8.666 & $\mathrm{C} 2 \mathrm{H}$ & 2.85 & $\mathrm{C} 2 \mathrm{H}$ & - & $\mathrm{C} 2 \mathrm{H}$ & 12.7 & $\mathrm{C} 2 \mathrm{H}$ & 9.485 \\
\hline $\mathrm{C} 2 \mathrm{~V}$ & 6.167 & $\mathrm{C} 2 \mathrm{~V}$ & 4.374 & $\mathrm{C} 2 \mathrm{~V}$ & - & $\mathrm{C} 2 \mathrm{~V}$ & 11.37 & $\mathrm{C} 2 \mathrm{~V}$ & 8.662 \\
\hline $\mathrm{C} 2 \mathrm{~A}$ & 7.214 & $\mathrm{C} 2 \mathrm{~A}$ & 4.153 & $\mathrm{C} 2 \mathrm{~A}$ & - & $\mathrm{C} 2 \mathrm{~A}$ & 8.176 & $\mathrm{C} 2 \mathrm{~A}$ & 7.395 \\
\hline $\mathrm{C} 3 \mathrm{H}$ & 6.682 & $\mathrm{C} 3 \mathrm{H}$ & 5.975 & $\mathrm{C} 3 \mathrm{H}$ & 7.021 & $\mathrm{C} 3 \mathrm{H}$ & 5.501 & $\mathrm{C} 3 \mathrm{H}$ & 3.836 \\
\hline C3V & 6.814 & C3V & 4.988 & C3V & 4.255 & C3V & 6.003 & C3V & 5.278 \\
\hline C3A & 8.051 & C3A & 3.308 & C3A & 7.43 & C3A & 8.202 & C3A & 5.178 \\
\hline $\mathrm{C} 4 \mathrm{H}$ & 7.925 & $\mathrm{C} 4 \mathrm{H}$ & 6.097 & $\mathrm{C} 4 \mathrm{H}$ & - & $\mathrm{C} 4 \mathrm{H}$ & 8.557 & $\mathrm{C} 4 \mathrm{H}$ & 12.07 \\
\hline C4V & 7.097 & $\mathrm{C} 4 \mathrm{~V}$ & 4.472 & C4V & - & C4V & 7.791 & $\mathrm{C} 4 \mathrm{~V}$ & 6.038 \\
\hline C4A & 7.783 & C4A & 3.274 & C4A & - & C4A & 10.2 & C4A & 5.946 \\
\hline $\mathrm{C} 5 \mathrm{H}$ & 6.582 & $\mathrm{C} 5 \mathrm{H}$ & 2.938 & $\mathrm{C} 5 \mathrm{H}$ & 4.624 & $\mathrm{C} 5 \mathrm{H}$ & 14.97 & $\mathrm{C} 5 \mathrm{H}$ & 13.22 \\
\hline C5V & 6.741 & C5V & 2.822 & C5V & 3.868 & C5V & 12.58 & C5V & 6.779 \\
\hline C5A & 5.698 & C5A & 2.945 & C5A & 3.319 & C5A & 13.47 & C5A & 8.802 \\
\hline $\mathrm{C} 7 \mathrm{H}$ & 8.18 & $\mathrm{C} 7 \mathrm{H}$ & 6.424 & $\mathrm{C} 7 \mathrm{H}$ & - & $\mathrm{C} 7 \mathrm{H}$ & 7.386 & $\mathrm{C} 7 \mathrm{H}$ & 8.857 \\
\hline C7V & 4.549 & C7V & 6.788 & C7V & - & C7V & 5.911 & C7V & 7.402 \\
\hline C7A & 5.438 & C7A & 4.232 & C7A & - & C7A & 7.945 & C7A & 6.01 \\
\hline $\mathrm{C} 8 \mathrm{H}$ & 5.197 & $\mathrm{C} 8 \mathrm{H}$ & 5.97 & $\mathrm{C} 8 \mathrm{H}$ & 5.061 & $\mathrm{C} 8 \mathrm{H}$ & 6.261 & $\mathrm{C} 8 \mathrm{H}$ & 10.88 \\
\hline C8V & 6.858 & $\mathrm{C} 8 \mathrm{~V}$ & 7.439 & $\mathrm{C} 8 \mathrm{~V}$ & 5.192 & $\mathrm{C} 8 \mathrm{~V}$ & 6.417 & C8V & 7.401 \\
\hline $\mathrm{C} 8 \mathrm{~A}$ & 9.813 & C8A & 2.959 & C8A & 5.427 & $\mathrm{C} 8 \mathrm{~A}$ & 9.449 & C8A & 3.631 \\
\hline
\end{tabular}

In the following data, the spectrum display combines the $x$-axis as frequency and the $y$-axis as amplitude. The frequency itself will later use as a tool to detect the mechanical movement of the compressor system. While the amplitude determines how much the vibrational motion of the mechanical compressor system is between its parts. Machine vibration has several general terms 
including amplitude, frequency, spectrum, waveform, and many other terms. Amplitude is a measure of the magnitude of the force of the vibration, its size can be in the form of displacement (microns or mils), velocity $(\mathrm{mm} / \mathrm{s})$, and acceleration $\left(G^{\prime} \mathrm{s}\right.$ or $\left.\mathrm{mm} / \mathrm{s}^{2}\right)$. Frequency is the number of movements or cycles in a certain time span. Frequency units include revolutions per minute (RPM), revolutions per second $(\mathrm{Hz})$. The waveform is a graph of the movement of components with the $y$-axis as amplitude and the $x$-axis as time. The last is the spectrum which is the result of the Fast Fourier Transform calculation of the waveform and produces a graph of the ratio of the amplitude ( $y$-axis) and frequency (x-axis). The spectrum in the data below has the $y$-axis as the amplitude with the unit used is $\mathrm{mm} / \mathrm{s}$ RMS, while the $\mathrm{x}$-axis shows the frequency in $\mathrm{Hz}$. Several parameters that must be set to process analog signals into digital signals include the maximum frequency, the number of lines, and several other parameters.

Figure 2 shows cascade view of the velocity spectrum of vibration on compressor 1 in the piping system one has a dominant screw pass frequency in the low-pressure compressor. Screw pass frequency captured at $416.6 \mathrm{~Hz}$ (16.84 Order) and highest screw pass frequency amplitude 6.449 $\mathrm{mm} / \mathrm{s}$ RMS. It is acceptable condition from compressor vibration standard.

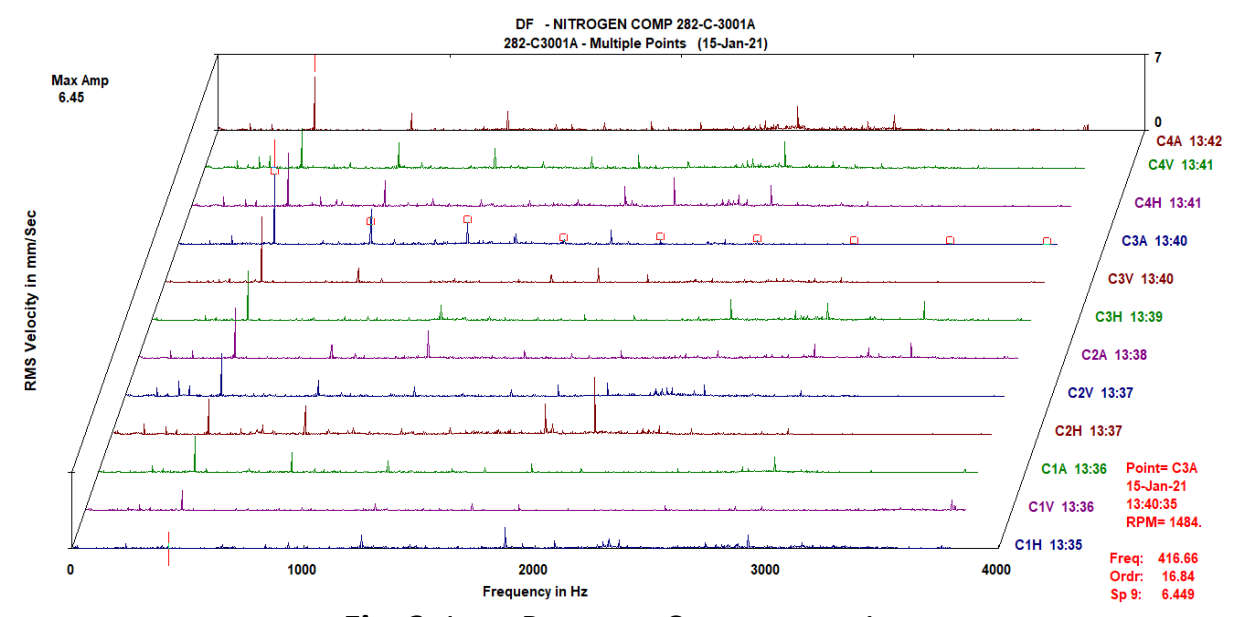

Fig. 2. Low-Pressure Compressor 1

Figure 3 shows cascade view of the velocity spectrum of vibration on compressor 1 in the piping system one has a dominant screw pass frequency in the high pass compressor. Screw pass frequency captured at $416.66 \mathrm{~Hz}$ (16.81 Order) and highest screw pass frequency amplitude $3.820 \mathrm{~mm} / \mathrm{s}$ RMS. It is acceptable condition from compressor vibration standard.

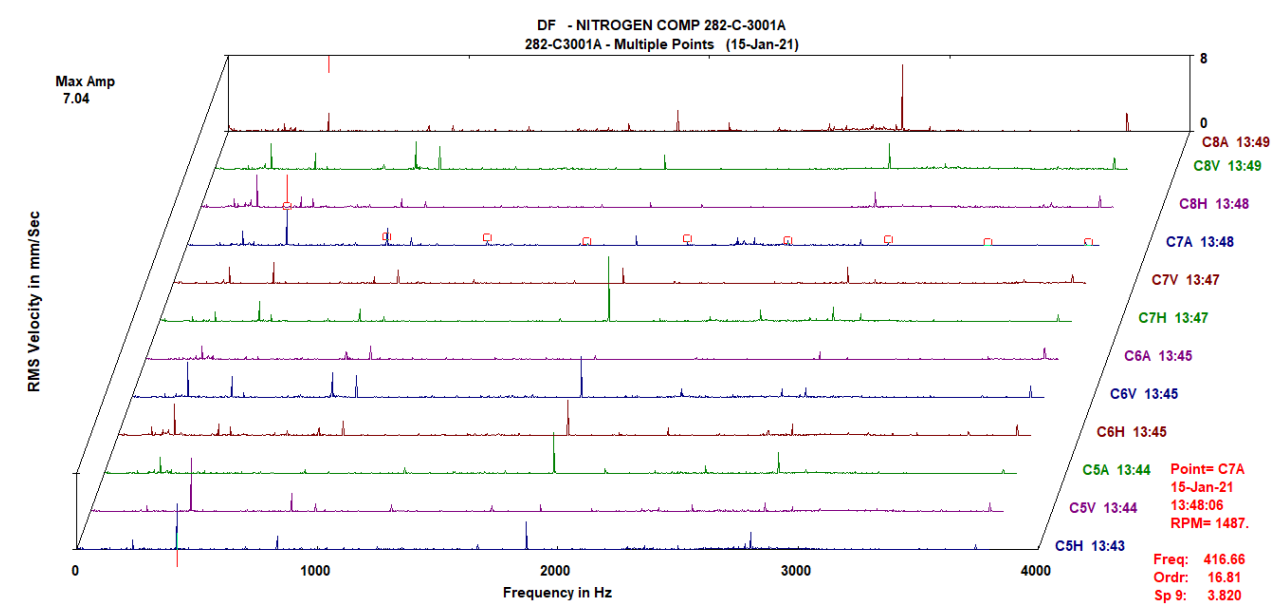

Fig. 3. High-Pressure Compressor 1 
Figure 4 shows cascade view of the velocity spectrum of vibration on compressor 2 in the piping system one has a dominant screw pass frequency in the low-pressure compressor. Screw pass frequency captured at $416.66 \mathrm{~Hz}$ (16.67 Order) and highest amplitude $6.449 \mathrm{~mm} / \mathrm{s}$ RMS. It is acceptable condition from compressor vibration standard.

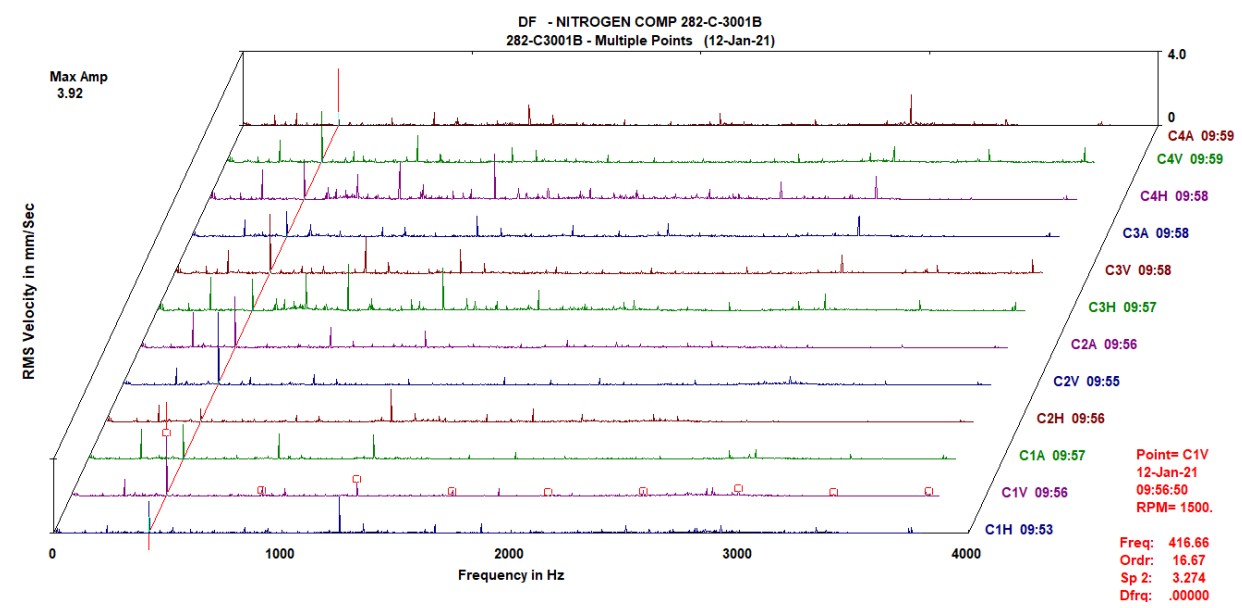

Fig. 4. Low-Pressure Compressor 2

Figure 5 shows cascade view of the velocity spectrum of vibration on compressor 2 in the piping system one has a dominant screw pass frequency in the high pass compressor. Screw pass frequency captured at $416.6 \mathrm{~Hz}$ (16.84 Order) and highest amplitude $3.274 \mathrm{~mm} / \mathrm{s}$ RMS. It is acceptable condition from compressor vibration standard.

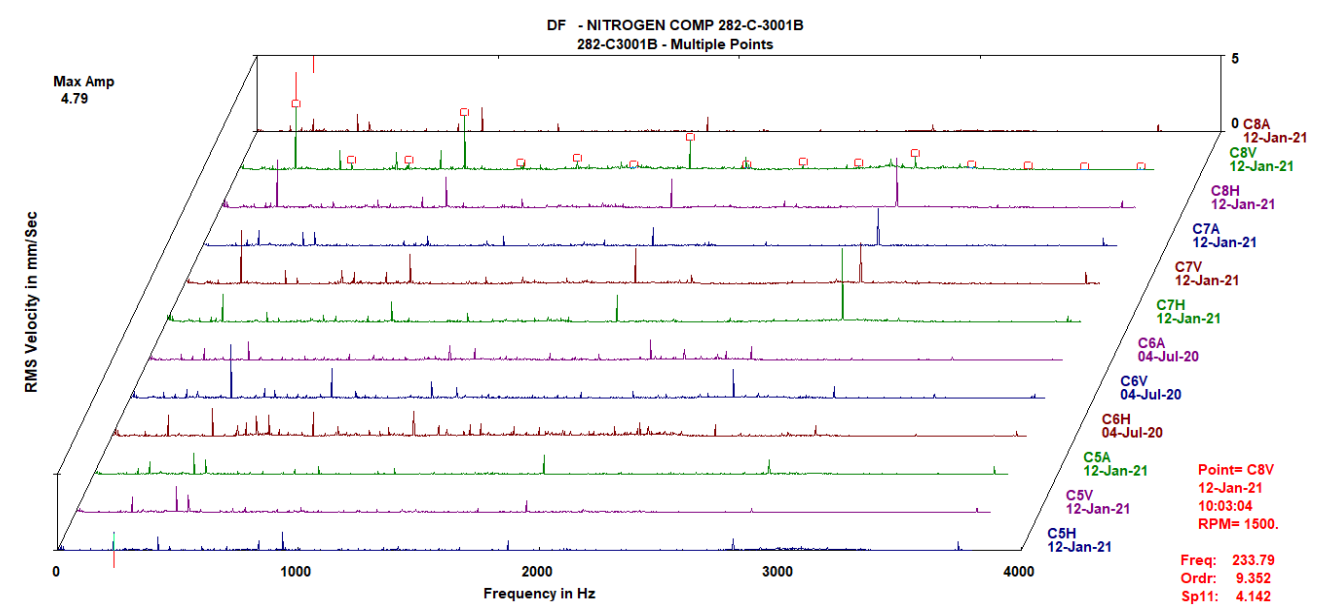

Fig. 5. High-Pressure Compressor 2

Figure 6 shows cascade view of the velocity spectrum of vibration on compressor 3, piping system two, which has a dominant screw pass frequency in the low-pressure compressor. Screw pass frequency captured at $453.63 \mathrm{~Hz}$ (18.64 Order) and highest amplitude $1.184 \mathrm{~mm} / \mathrm{s} \mathrm{RMS}$. It is acceptable condition from compressor vibration standard. 


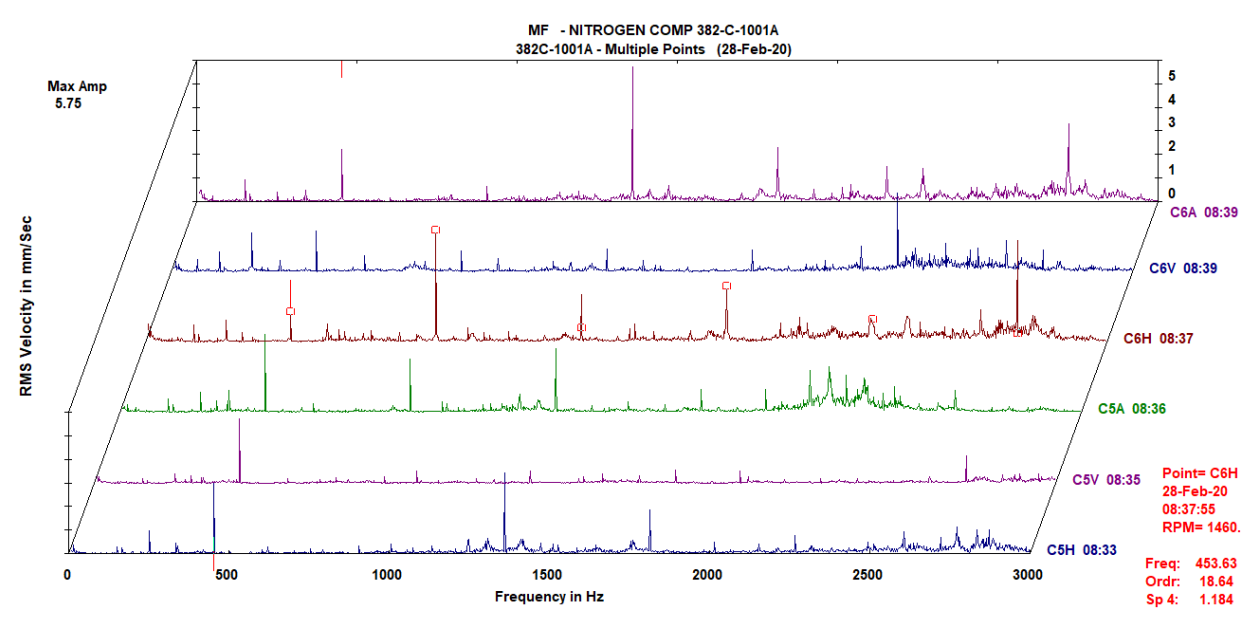

Fig. 6. Low-Pressure Compressor 3

Figure 7 shows cascade view of the velocity spectrum of vibration on compressor 3, piping system two, which has a dominant screw pass frequency in the high pass compressor. Screw pass frequency captured at $453.63 \mathrm{~Hz}$ (18.34 Order) and highest amplitude $3.944 \mathrm{~mm} / \mathrm{s}$ RMS. It is acceptable condition from compressor vibration standard.

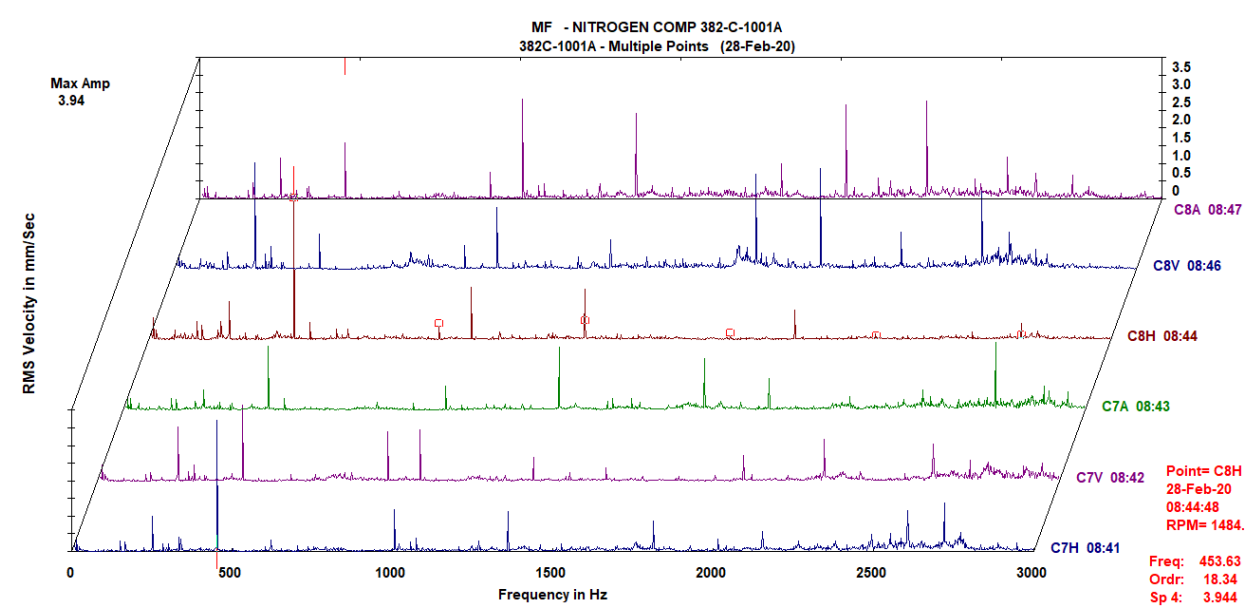

Fig. 7. High-Pressure Compressor 3

Figure 8 shows cascade view of the velocity spectrum of vibration on the compressor 4, piping system two has a dominant screw pass frequency in the low-pressure compressor. Screw pass frequency captured at $452.29 .6 \mathrm{~Hz}$ (17.96 Order) and highest amplitude $2.108 \mathrm{~mm} / \mathrm{s}$ RMS. It is acceptable condition from compressor vibration standard. 


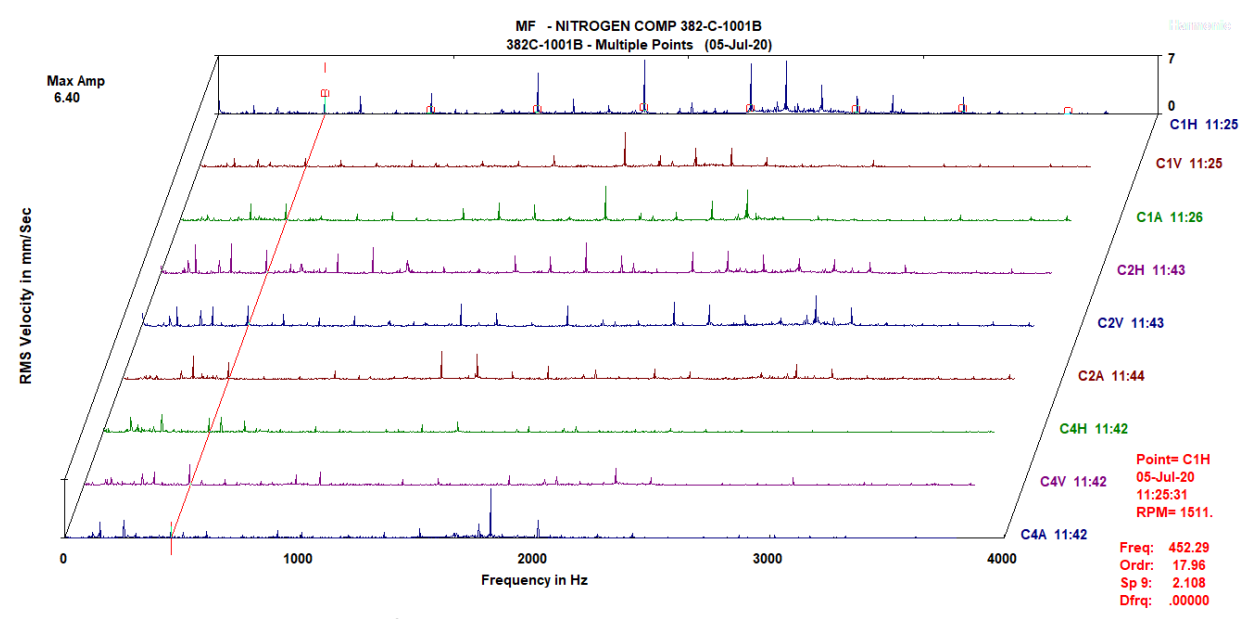

Fig. 8. Low-Pressure Compressor 4

Figure 9 shows cascade view of the velocity spectrum of vibration on the compressor 4, piping system two has a dominant screw pass frequency in the high pass compressor. Screw pass frequency captured at $452.29 \mathrm{~Hz}$ (17.95 Order) and highest amplitude $4.966 \mathrm{~mm} / \mathrm{s}$ RMS. It is acceptable condition from compressor vibration standard.

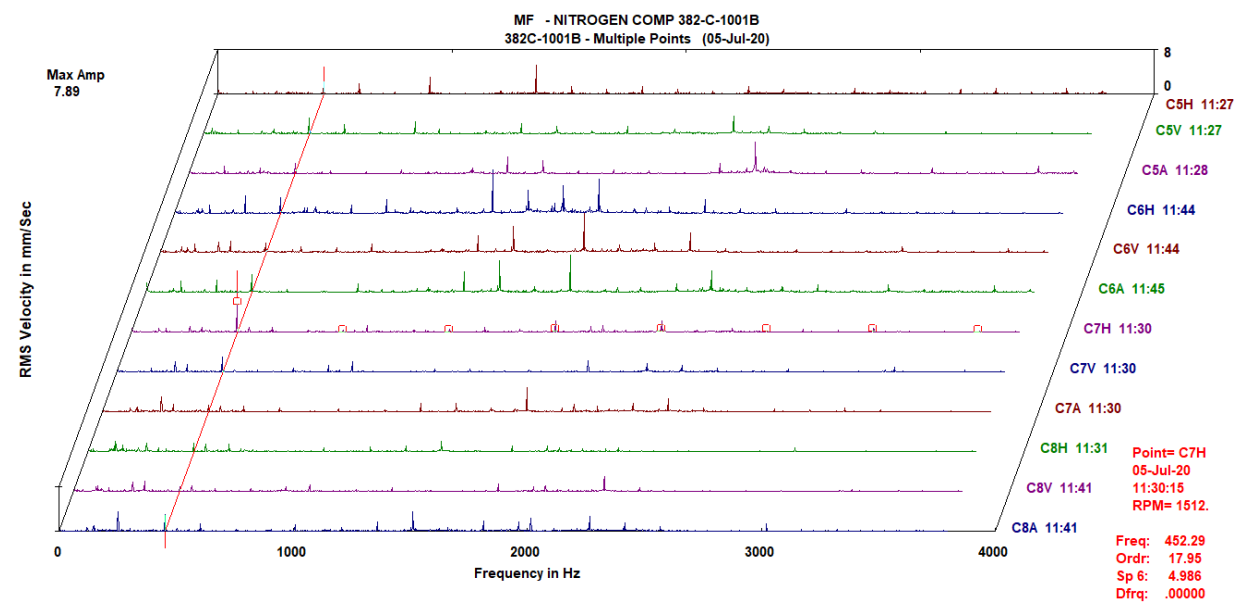

Fig. 9. High-Pressure Compressor 4

Figure 10 shows cascade view of the velocity spectrum of vibration on compressor 3 , piping system two has a dominant screw pass frequency in the low-pressure compressor. Screw pass frequency captured at $454.66 \mathrm{~Hz}$ (18.19 Order) and highest amplitude $7.541 \mathrm{~mm} / \mathrm{s}$ RMS. It is near limit of compressor vibration standard. 


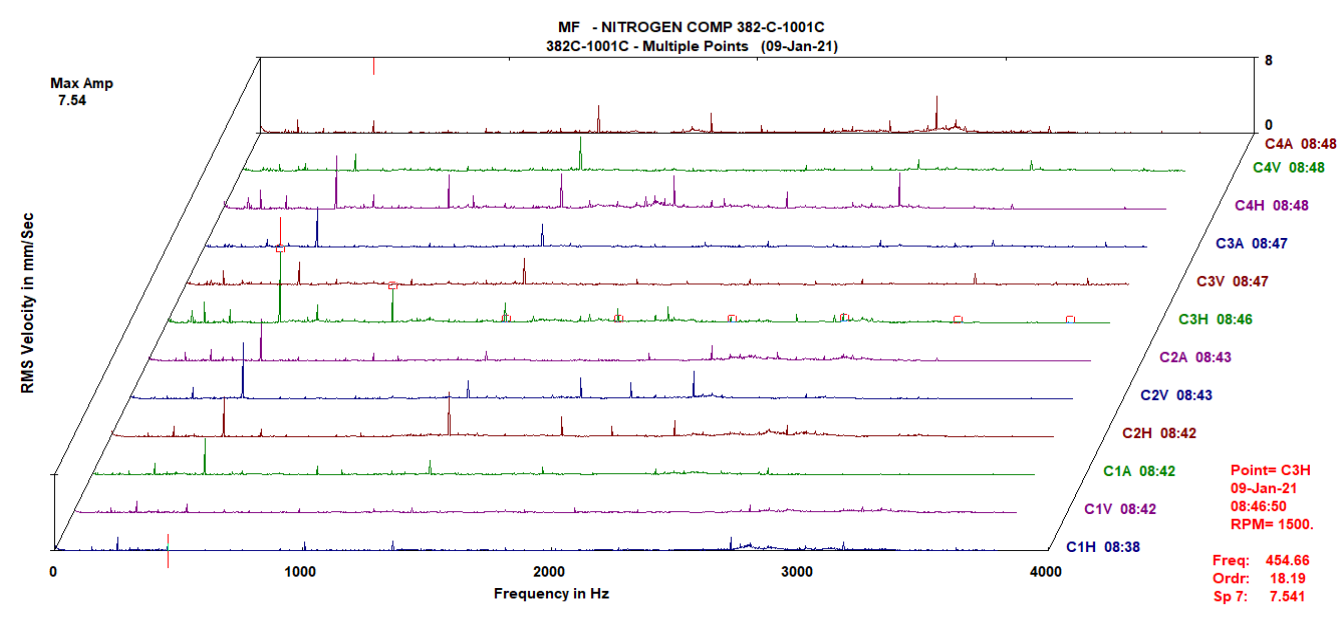

Fig. 10. Low-Pressure Compressor 5

Figure 11 shows cascade view of the velocity spectrum of vibration on compressor 3, piping system two has a dominant screw pass frequency in the high pass compressor. Highest frequency captured at $252.79 \mathrm{~Hz}$ (10.11 Order) with amplitude $4.663 \mathrm{~mm} / \mathrm{s}$ RMS. It is acceptable condition from compressor vibration standard.

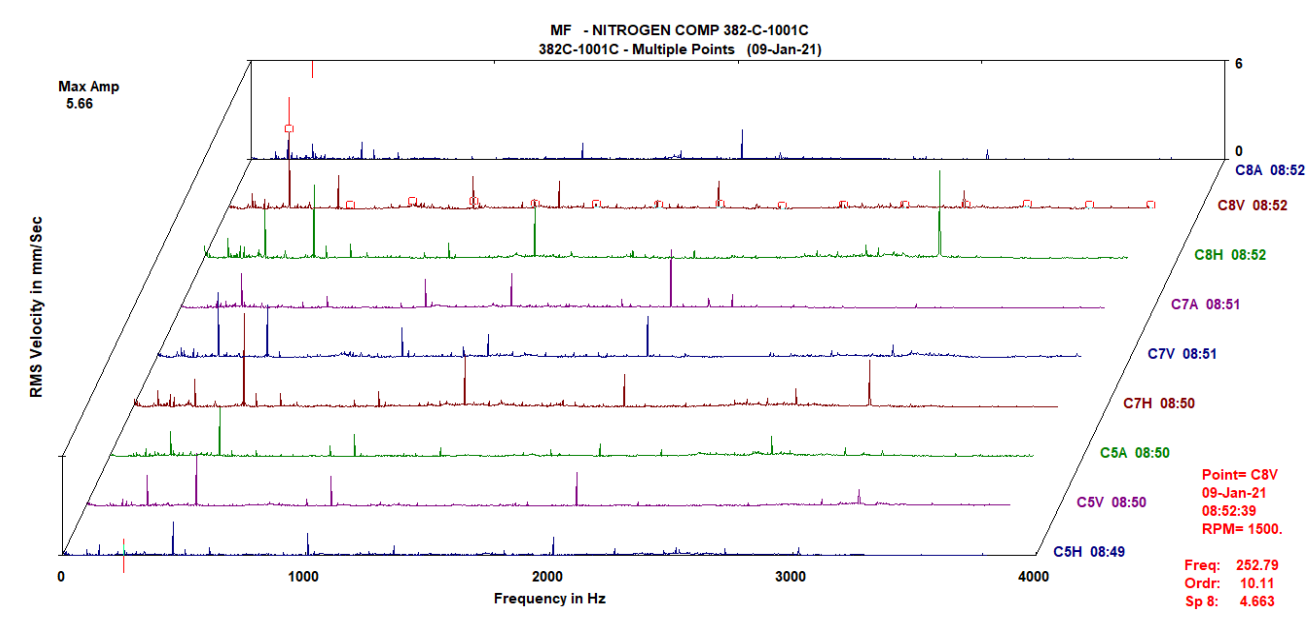

Fig. 11. High-Pressure Compressor 5

There is no data on the 6th compressor because it has suffered heavy damage and cannot operate.

\section{Numerical Simulation}

\subsection{CFD Model}

The first system has one equipment operating, and one equipment is in standby condition, compressor first and compressor second. In the second system, two equipment operates; compressor third and compressor 4th and two equipment standby; compressor fifth and compressor sixth. The nitrogen compressor comprises two components: an electric motor and two levels of a compressor, low pressure and high pressure. These two components connect to the bull gear, where the equipment's condition is in one product package.

There are two systems analyzed shown in Figure 12. The first compressor systems have a configuration of 2 compressor outputs combined into one with the condition of 1 valve after the combination of the two compressor outputs. 


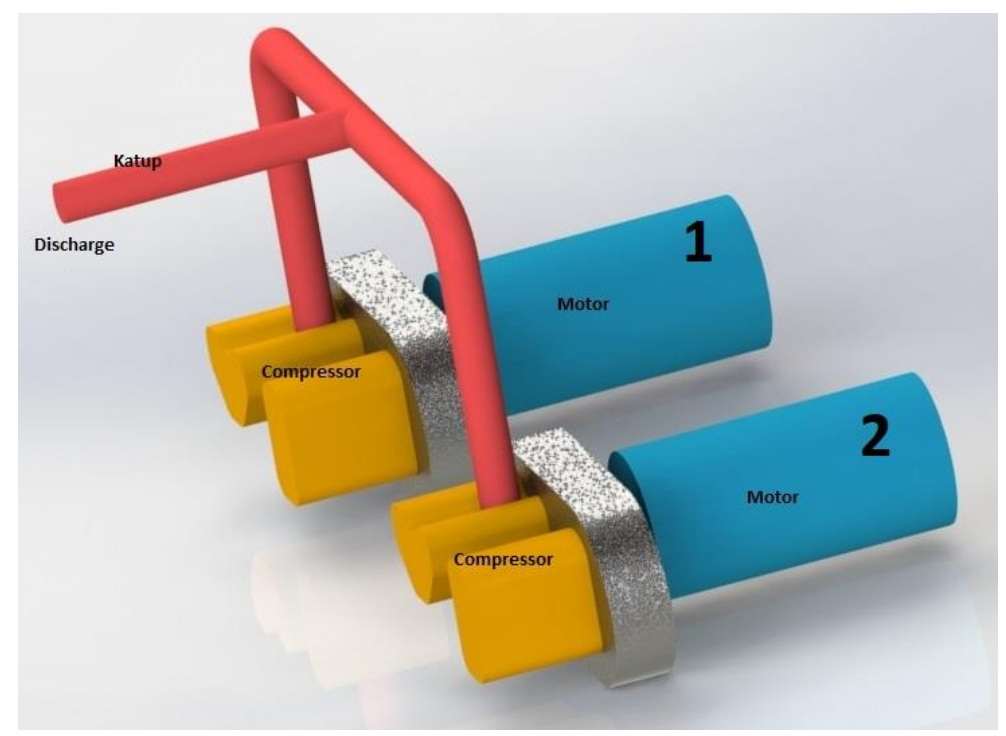

Fig. 12. 1st Compressor Piping System

Figure 13 shows that the second system has four compressor outputs combined into one with one valve after combining the four compressor outputs.

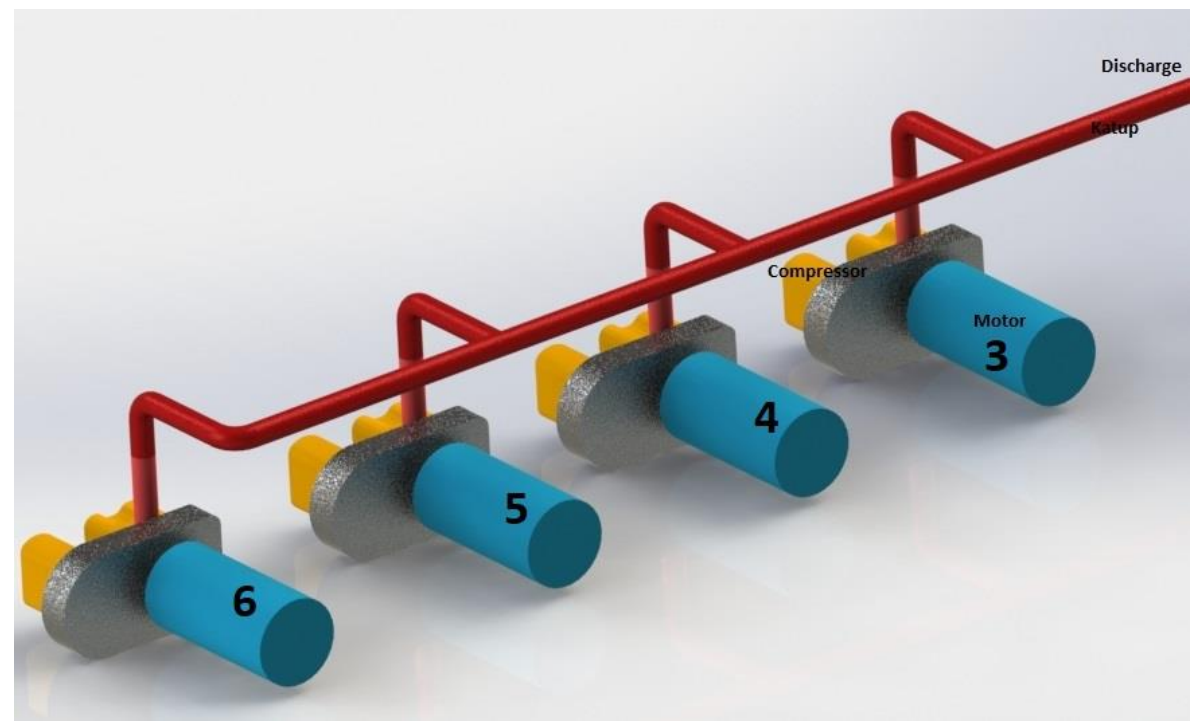

Fig. 13. 2nd Compressor Piping System

\section{Results and Discussions}

\section{$5.11^{\text {st }}$ System 2 Compressor, 1 Running}

As shown in Figure 14 and Figure 15, the first piping system shows that the first and second compressors reverse each other when operating or when standby. The flow in the standby compressor has a higher pressure reaching $10.72-11.82 \mathrm{~Pa}$. The picture above shows a backflow that will later contribute to the lifetime of the equipment due to pressure and condensed gas. 


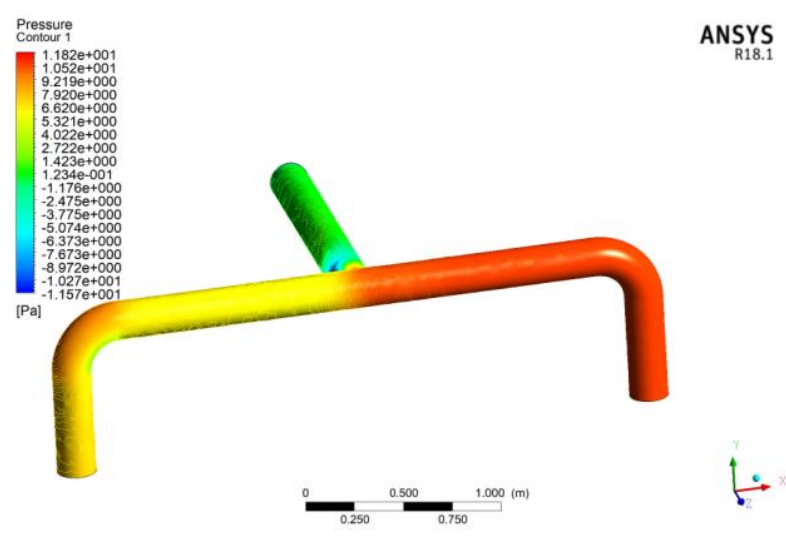

Fig. 14. 1st Valve System inlet A Pressure Contour

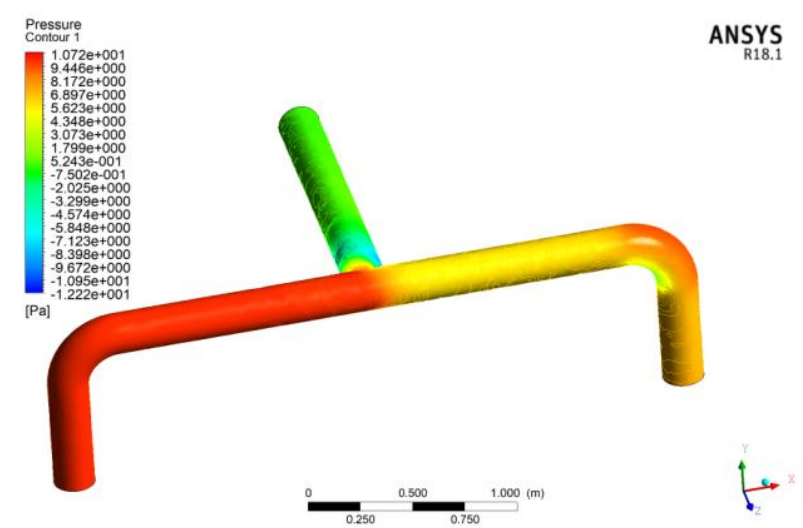

Fig. 15. 2nd Valve System inlet B Pressure Contour

\section{$5.22^{\text {nd }}$ System 4 Compressor, 2 Running}

As shown in Figure 16 and Figure 17, the second piping system with the third compressor and the fourth compressor operating. Analyze shows that the pipeline flow to the fifth and sixth compressors is higher than the gas discharge flow. Pressure under operating conditions as above produces pressures up to $42.80 \mathrm{~Pa}$.

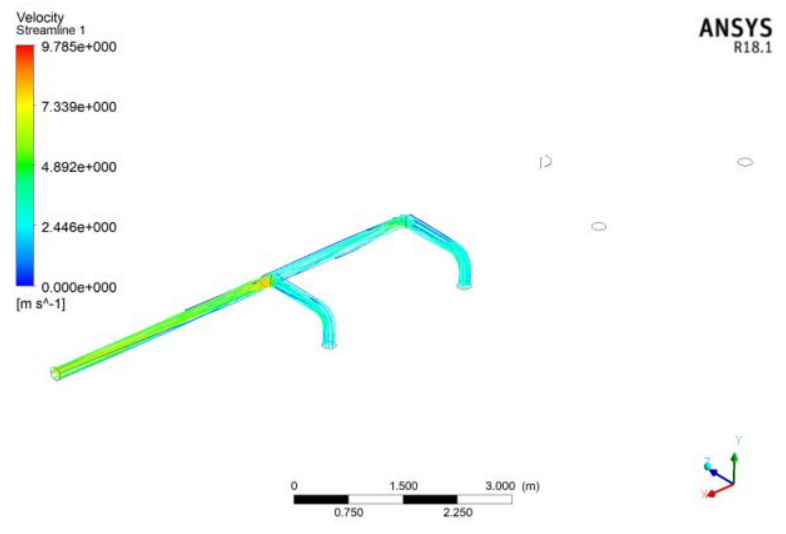

Fig. 16. 2nd Piping System $3^{\text {rd }}$ and $4^{\text {th }}$ Compressor Running Streamline

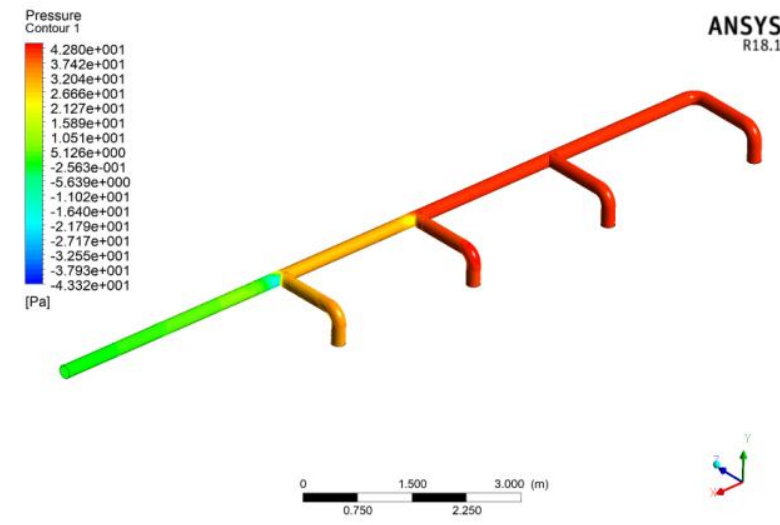

Fig. 17. 2nd Piping System $3^{\text {rd }}$ and $4^{\text {th }}$ Compressor Running Contour

As shown in Figure 18 and Figure 19, the second piping system with the third compressor and the fifth compressor operating. Analyze shows that the pipeline flow to the sixth compressor is higher than the gas discharge flow. The pressure in the pipeline to the fourth compressor is more stable with a pressure ranging from $27.77-33.22 \mathrm{~Pa}$. Pressure under operating conditions as above produces the highest pressure on the sixth compressor up to $44.12 \mathrm{~Pa}$. 


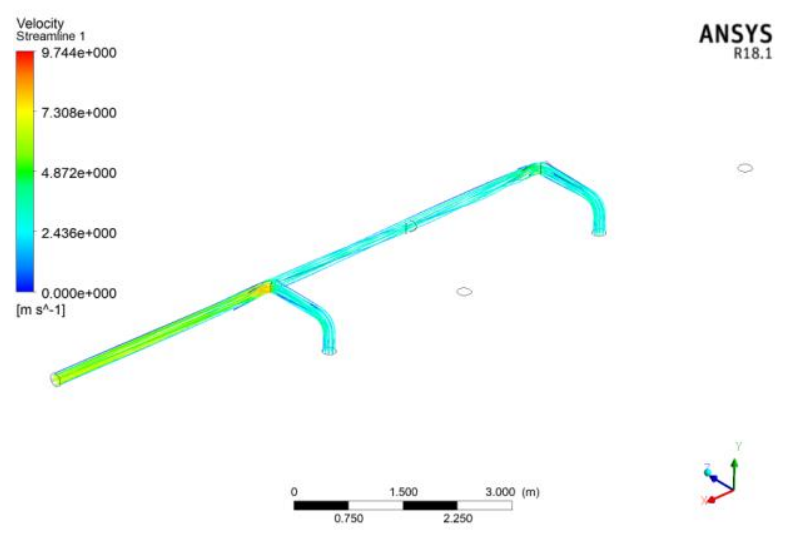

Fig. 18. 2nd Valve System $3^{\text {rd }}$ and $5^{\text {th }}$ Compressor Running Streamline

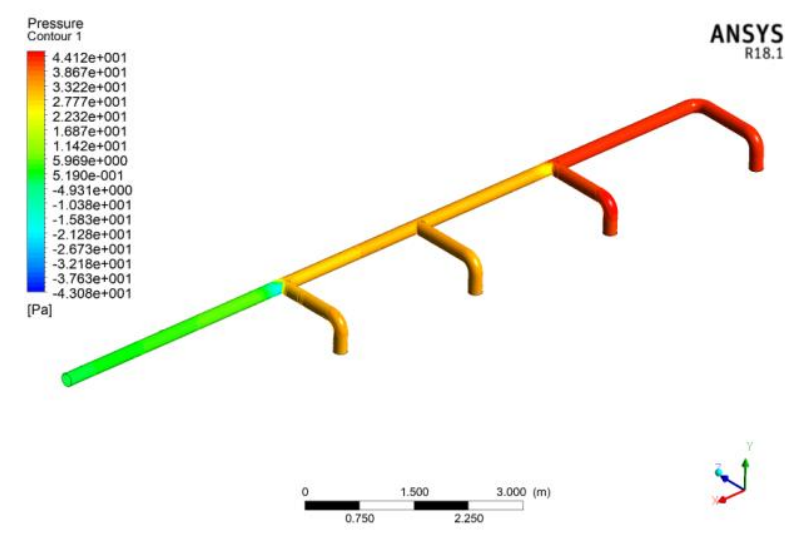

Fig. 19. 2nd Valve System $3^{\text {rd }}$ and $5^{\text {th }}$ Compressor Running Contour

As shown in Figure 20 and Figure 21, the second piping system with the third compressor and the sixth compressor in operation shows that the pipeline flow to all compressors is equal. The pressure after the third compressor's output experiences a drastic pressure drop because there is a confluence of two flows so that turbulent flow occurs, resulting in a higher speed. The pressure at each pipeline to the compressor ranges from $34.27-39.40 \mathrm{~Pa}$.

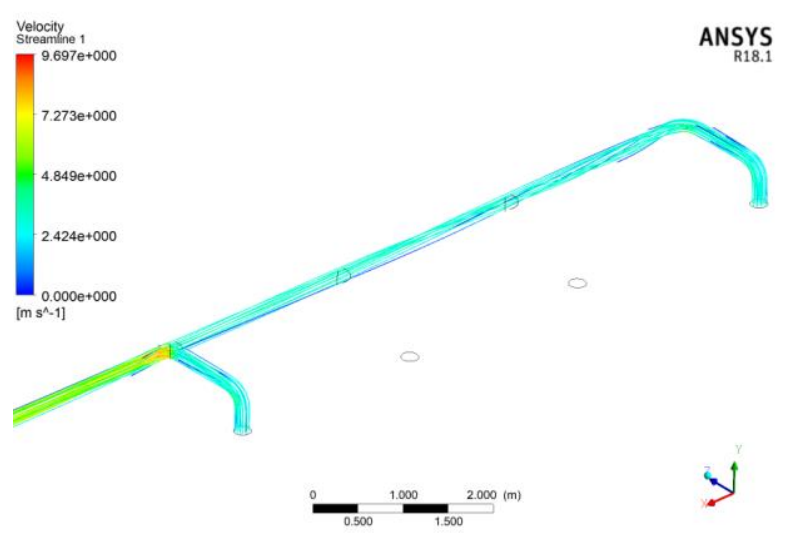

Fig. 20. 2nd Valve System $3^{\text {rd }}$ and $6^{\text {th }}$ Compressor Running Streamline

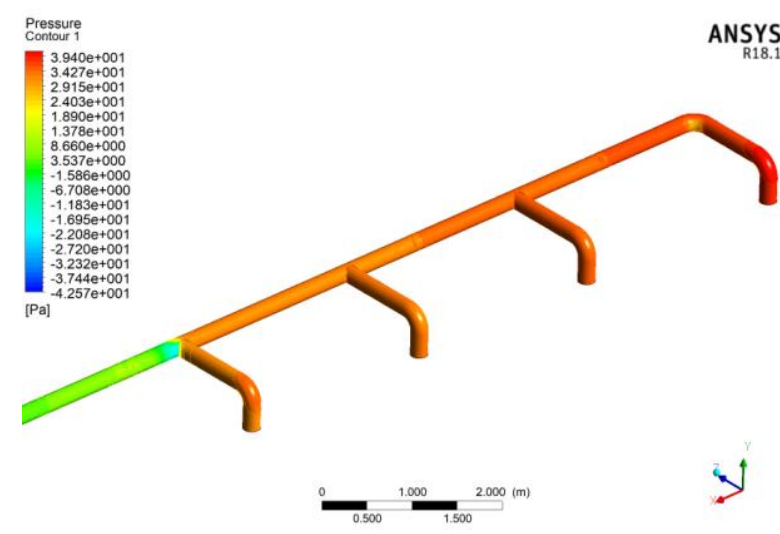

Fig. 21. 2nd Valve System $3^{\text {rd }}$ and $6^{\text {th }}$ Compressor Running Contour

As shown in Figure 22 and Figure 23, the second piping system with the fourth compressor and the fifth compressor in operation shows the pipeline flow to all sixth compressors, in the opposite direction of flow with higher discharge. The pressure after the fourth compressor's output experiences a drastic drop in pressure because there is a confluence of two flows so that turbulent flow occurs, resulting in a higher speed. The pressure on the third compressor is relatively more minor, ranging from $4.4-9.78 \mathrm{~Pa}$. The highest pressure in the pipeline to the sixth compressor reaches $47.32 \mathrm{~Pa}$. 


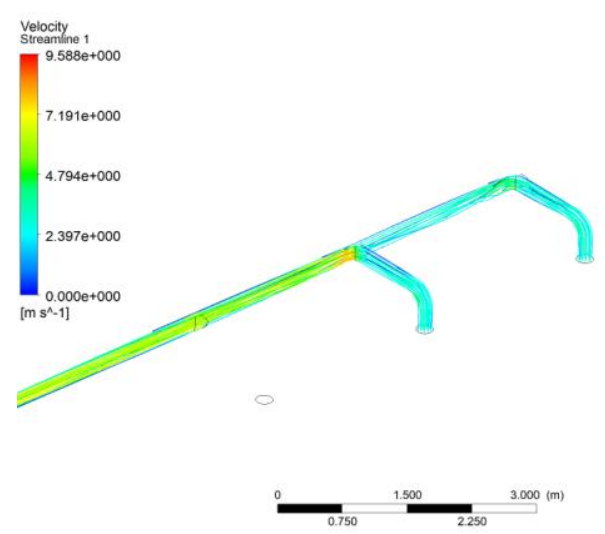

Fig. 22. 2nd Valve System $4^{\text {th }}$ and $5^{\text {th }}$ Compressor Running Streamline

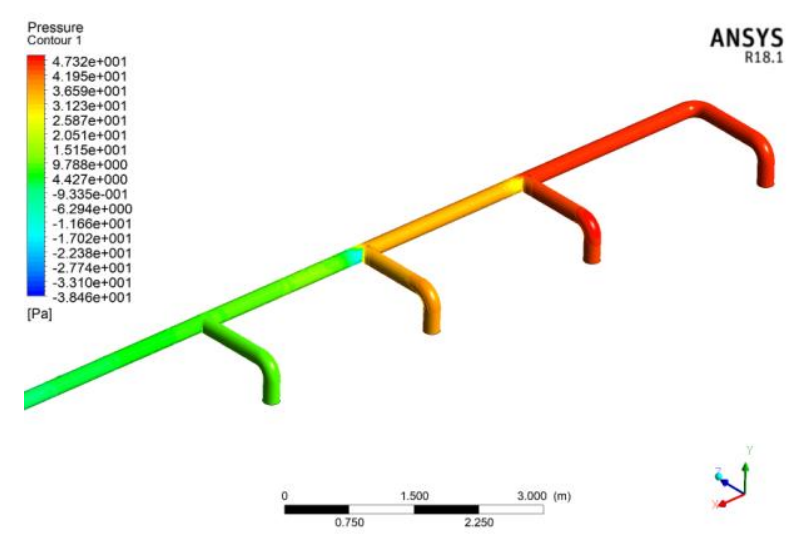

Fig. 23. 2nd Valve System $4^{\text {th }}$ and $5^{\text {th }}$ Compressor Running Contour

As shown in Figure 24 and Figure 25, the second piping system with the fourth compressor and the sixth compressor in operation shows that the pipe flow to all compressors is evenly distributing in the fourth, fifth, and sixth compressors. The pressure after the fourth compressor's output experiences a drastic drop in pressure because there is a confluence of two flows so that turbulent flow occurs, resulting in a higher speed. The pressure on the third compressor is relatively more minor, ranging from $2.4-7.48 \mathrm{~Pa}$. The highest pressure in the pipe flow reaches $42.66 \mathrm{~Pa}$.

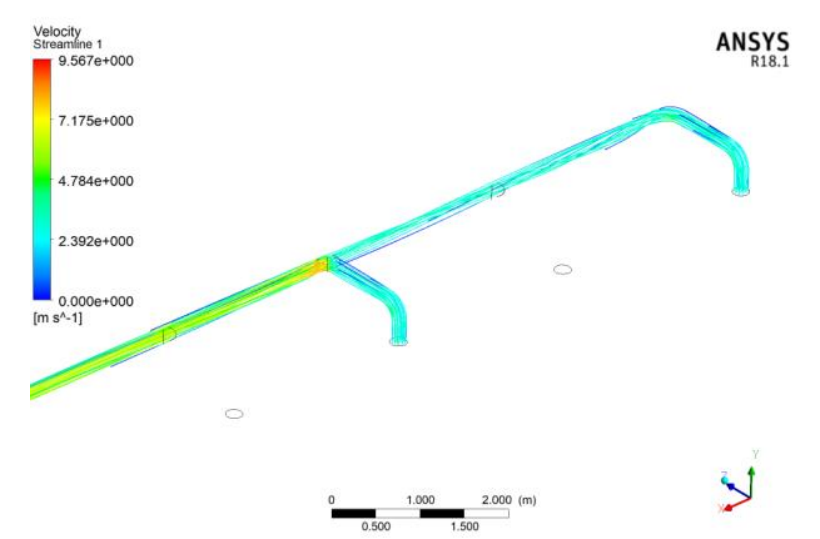

Fig. 24. 2nd Valve System $4^{\text {th }}$ and $6^{\text {th }}$ Compressor Running Streamline

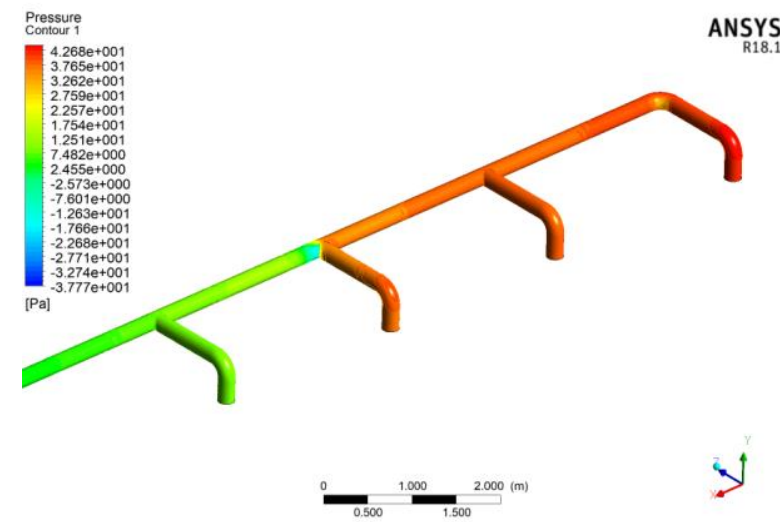

Fig. 25. 2nd Valve System $4^{\text {th }}$ and $6^{\text {th }}$ Compressor Running Contour

As shown in Figure 26 and Figure 27, the second piping system with the fifth compressor and the sixth compressor in operation shows that the pipeline flow to all compressors is smaller in the third and fourth compressors. The pressure after the fifth compressor output experiences a drastic drop in pressure because there is a confluence of two flows, so that flow turbulence occurs, resulting in a higher speed. The third and fourth compressors' pressure is relatively more minor, ranging from 2.17 - 5.27 $\mathrm{Pa}$. The highest pressure in the pipeline reaches $44.79 \mathrm{~Pa}$, which is at the fifth and sixth compressors operating. 


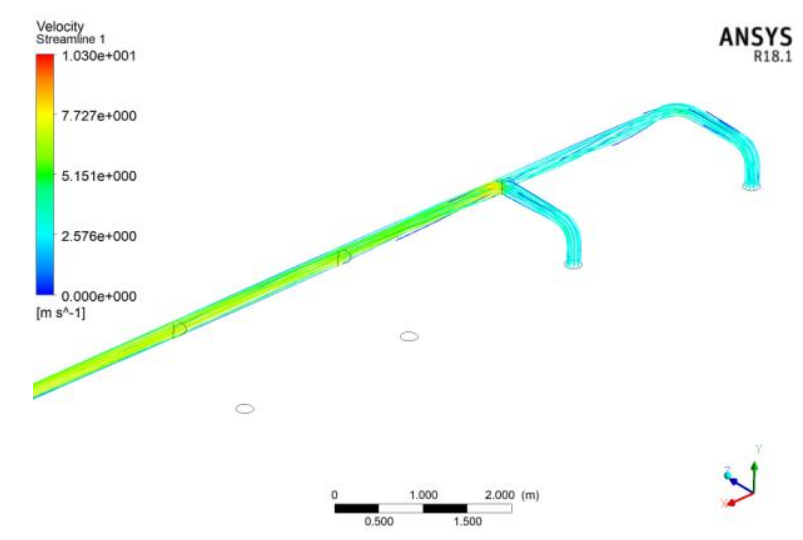

Fig. 26. 2nd Valve System $5^{\text {th }}$ and $6^{\text {th }}$ Compressor Running Streamline

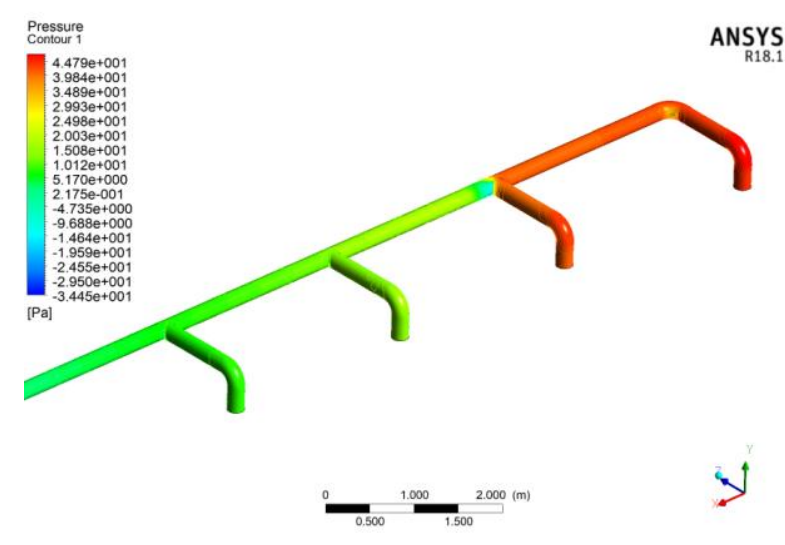

Fig. 27. 2nd Valve System $5^{\text {th }}$ and $6^{\text {th }}$ Compressor Running Contour

\section{Conclusions}

High pressure in the gas flow will cause the gas to compress and possibly condense also give a high impact on the standby compressor-further experiments related to the possibility of condensation in this flow system. In the first system, the two compressors are in good condition, but this does not rule out the possibility that the compressor with longer standby will be damaged more quickly. While the dual system, four compressors, is in standby condition more quickly to severe damage, especially at the sixth compressor due to more backflow and pressure to the line.

The recommendation regarding backflow and condensation flow is to add a valve at each compressor outlet. This recommendation prevents direct pressure to the compressor or the condensed fluid from the gas flowing and enter the compressor.

\section{Acknowledgement}

This research was supported by Tiara Vibrasindo Pratama and Pertamina EP Company.

\section{References}

[1] He, Zhilong, Yaoxiang Han, Wenqing Chen, Minglong Zhou, and Ziwen Xing. "Noise control of a two-stage screw refrigeration compressor." Applied Acoustics 167 (2020): 107383. https://doi.org/10.1016/i.apacoust.2020.107383

[2] He, Zhilong, Dantong Li, Yaoxiang Han, Minglong Zhou, Ziwen Xing, and Xiaolin Wang. "Noise control of a twinscrew refrigeration compressor." International Journal of Refrigeration 124 (2021): $30-42$. https://doi.org/10.1016/j.ijrefrig.2020.12.008

[3] Xiong, Xiu, Li Li, and Xiao-qing Zhou. "Numerical Analysis and Optimization Research on Backflow Effect of Cooling Tower." Procedia Engineering 205 (2017): 2003-2010. https://doi.org/10.1016/i.proeng.2017.10.073

[4] Sugimura, Akihiko, A. A. Vakulenko, and A. V. Zakharov. "The effect of backflow on the field-induced director alignment process: Nuclear Magnetic Resonance study and theoretical analysis." Physics Procedia 14 (2011): $102-$ 114. https://doi.org/10.1016/i.phpro.2011.05.021

[5] Cheng, Z., T. O. Jelly, S. J. Illingworth, I. Marusic, and A. S. H. Ooi. "Forcing frequency effects on turbulence dynamics in pulsatile pipe flow." International Journal of Heat and Fluid Flow 82 (2020): 108538. https://doi.org/10.1016/j.ijheatfluidflow.2020.108538

[6] Ilker, Pelin, and Mehmet Sorgun. "Performance of turbulence models for single phase and liquid-solid slurry flows in pressurized pipe systems." Ocean Engineering $214 \quad$ (2020): 107711. https://doi.org/10.1016/i.oceaneng.2020.107711

[7] Islam, A. S. M. Atiqul, and D. J. Bergstrom. "Modelling bubble induced turbulence for gas-liquid bubbly flow in a vertical pipe." Chemical Engineering Science 197 (2019): 159-171. https://doi.org/10.1016/i.ces.2018.11.061

[8] Skartlien, Roar, Sven Nuland, and Joar E. Amundsen. "Simultaneous entrainment of oil and water droplets in high Reynolds number gas turbulence in horizontal pipe flow." International Journal of Multiphase Flow 37, no. 10 (2011): 1282-1293. https://doi.org/10.1016/j.ijmultiphaseflow.2011.07.006 
[9] Sulistyawati, Wiwin, and Agus S. Pamitran. "Warp-chine on pentamaran hydrodynamics considering to reduction in ship power energy." Energy Procedia 156 (2019): 463-468. https://doi.org/10.1016/i.egypro.2018.11.082

[10] Gunawan, Yanuar, and K. T. Waskito. "Determination the optimum location for microbubble drag reduction method in self propelled barge model; an experimental approach." Energy Reports 6, no. 2 (2020): 774-783. https://doi.org/10.1016/j.egyr.2019.11.157

[11] Malik, M., and Martin Skote. "A linear system for pipe flow stability analysis allowing for boundary condition modifications." Computers \& Fluids 192 (2019): 104267. https://doi.org/10.1016/i.compfluid.2019.104267

[12] Sikora, Małgorzata, and Tadeusz Bohdal. "Heat and flow investigation of NOVEC649 refrigerant condensation in pipe minichannels." Energy 209 (2020): 118447. https://doi.org/10.1016/i.energy.2020.118447

[13] He, Guoxi, Yansong Li, Binbin Yin, Liying Sun, and Yongtu Liang. "Numerical simulation of vapor condensation in gas-water stratified wavy pipe flow with varying interface location." International Journal of Heat and Mass Transfer 115 (2017): 635-651. https://doi.org/10.1016/j.ijheatmasstransfer.2017.08.069

[14] Li, Shulei, Yiqiang Jiang, Weihua Cai, Haochun Zhang, and Fengzhi Li. "Numerical study on condensation heat transfer and pressure drop characteristics of methane upward flow in a spiral pipe under sloshing condition." International Journal of Heat and Mass Transfer $129 \quad$ (2019): $310-325$. https://doi.org/10.1016/i.ijheatmasstransfer.2018.09.108

[15] Sun, Wan, Tao Xu, Yu Hou, Zaiyong Ma, and Luteng Zhang. "Numerical investigation of nitrogen condensation flow over airfoil in cryogenic wind tunnel." Cryogenics 111 (2020): 103165. https://doi.org/10.1016/i.cryogenics.2020.103165

[16] Zhu, Shao-Long, Yan Li, Rui-Ping Zhang, Yuan Tang, Li-Min Qiu, and Xiao-Qin Zhi. "Experimental study on the condensation characteristics of nitrogen with non-condensable gas." Cryogenics 98 (2019): 29-38. https://doi.org/10.1016/i.cryogenics.2018.12.007

[17] Datta, Priyankan, Aranyak Chakravarty, Ritabrata Saha, Shouvik Chaudhuri, Koushik Ghosh, Achintya Mukhopadhyay, Swarnendu Sen, Anu Dutta, and Priyanshu Goyal. "Experimental investigation on the effect of initial pressure conditions during steam-water direct contact condensation in a horizontal pipe geometry." International Communications in Heat and Mass Transfer $121 \quad$ (2021): 105082. https://doi.org/10.1016/i.icheatmasstransfer.2020.105082

[18] Yang, Shengmei, Hua Ouyang, Yadong Wu, Lee Wang, Lu Mei, and Hongdan Wang. "CFD simulation for the internal pressure characteristics of an oil-injected twin-screw refrigeration compressor." International Journal of Refrigeration 126 (2021): 143-154. https://doi.org/10.1016/i.ijrefrig.2021.01.020

[19] Zhang, Zhao, and Weifeng Wu. "Numerical investigation of thermal deformation of meshing pairs in single screw compressor." Applied $\quad$ Thermal $\quad$ Engineering $188 \quad$ (2021): 116614. https://doi.org/10.1016/j.applthermaleng.2021.116614

[20] Wang, Chuang, Ziwen Xing, Wenqing Chen, Shizhong Sun, and Zhilong He. "Analysis of the leakage in a waterlubricated twin-screw air compressor." Applied Thermal Engineering 155 (2019): 217-225. https://doi.org/10.1016/j.applthermaleng.2019.04.001

[21] Marušić-Paloka, Eduard, and Igor Pažanin. "Effects of boundary roughness and inertia on the fluid flow through a corrugated pipe and the formula for the Darcy-Weisbach friction coefficient." International Journal of Engineering Science 152 (2020): 103293. https://doi.org/10.1016/j.ijengsci.2020.103293

[22] Zhao, Xinwei, Hongkun Li, Shuhua Yang, Zhenfang Fan, Jiannan Dong, and Hongwei Cao. "Blade vibration measurement and numerical analysis of a mistuned industrial impeller in a single-stage centrifugal compressor." Journal of Sound and Vibration 501 (2021): 116068. https://doi.org/10.1016/i.jsv.2021.116068

[23] Sun, Hai'ou, Aoyu Ren, Yanhua Wang, Mingfei Zhang, and Tao Sun. "Deformation and vibration analysis of compressor rotor blades based on fluid-structure coupling." Engineering Failure Analysis 122 (2021): 105216. https://doi.org/10.1016/i.engfailanal.2021.105216

[24] Rabby, Md Insiat Islam, Siti Ujila Masuri, Ahmad Syakir Fariz Samsul Kamal, Zulkiflle Leman, Abdul Aziz Hairuddin, and Nuraini Abdul Aziz. "Flow Characteristics of Disk Bypass Pipeline Inspection Gauge (PIG) in Natural Gas Pipelines using Computational Fluid Dynamics." CFD Letters 13, no. 4 (2021): 11-37. https://doi.org/10.37934/cfdl.13.4.1137

[25] Oo, Ye Min, Makatar Wae-hayee, and Chayut Nuntadusit. "Experimental and Numerical Study on the Effect of Teardrop Dimple/Protrusion Spacing on Flow Structure and Heat Transfer Characteristics." Journal of Advanced Research in Experimental Fluid Mechanics and Heat Transfer 2, no. 1 (2020): 17-32.

[26] Mahat, Rahimah, Sharidan Shafie, and Fatihhi Januddi. "Numerical Analysis of Mixed Convection Flow Past a Symmetric Cylinder with Viscous Dissipation in Viscoelastic Nanofluid." CFD Letters 13, no. 2 (2021): 12-28. https://doi.org/10.37934/cfdl.13.2.1228

[27] Azman, Azraf, Mohd Zamri Yusoff, Azfarizal Mukhtar, Prem Gunnasegaran, Nasri A. Hamid, and Ng Khai Ching. "Numerical Study of Heat Transfer Enhancement for Mono and Hybrid Nanofluids Flow in a Straight Pipe." CFD Letters 13, no. 2 (2021): 49-61. https://doi.org/10.37934/cfdl.13.2.4961 
[28] Musa, Solihin, Nor Azwadi Che Sidik, Siti Nurul Akmal Yusof, and Erdiwansyah. "Analysis of Internal Flow in Bag Filter by Different Inlet Angle." Journal of Advanced Research in Numerical Heat Transfer 3, no. 1 (2020): 12-24.

[29] Gunawan, Allessandro Setyo Anggito Utomo, F. Fariz, and S. A. Lambang. "Reduction of Drag Resistance by Pressure Drop in Pipeline with 3-Dimensional Design Optimization." Journal of Advanced Research in Fluid Mechanics and Thermal Sciences 83, no. 2 (2021): 44-53. https://doi.org/10.37934/arfmts.83.2.4453 